\title{
BLOOD SUPPLY OF THE COENDOU (Sphiggurus spp. Cuvier, 1825 - (RODENTIA: MAMMALIA) UTERUS AND OVARIES
}

\author{
MACHADO, G.V. ${ }^{1}$; GONÇALVES, P.R. ${ }^{2}$; PARIZZI, A. ${ }^{2}$ MIGLINO, M.A. ; SANTOS, T.C. ${ }^{4}$ \\ ${ }^{1}$ UFPR/Campus Palotina; \\ ${ }^{2}$ UPF (Universidade de Passo Fundo); \\ ${ }^{3} \mathrm{FMVZ/USP}$; \\ ${ }^{4}$ Doutoranda - FMVZ/USP.
}

The coendou (Sphiggurus spp.) belongs to the Erethizontidae family. Is a rodent with peculiar habits, endowed with prehensile members feeding basically on fruits and leaves. Coendou's morphology is pratically unknown, particularly in regard to the aspects of its vascular system. The aim of the present research work is to contribute with data regarding the arterial vascular system of the feminine genital organs of those animals, particularly the ovaries and uterus. For this purpose, three adult females were used, one of them pregnant already found dead at the side of highways of the Western Region of Paraná State. At the laboratory, they had the arterial vascular system injected with a colored solution of Neoprene latex. Soon after, they were fixed in a $10 \%$ formalin aqueous solutionand dissected. The dissections allowed to observe that: a) the ovaries of the coendou are irrigated, in an exclusive way, by the ovarian arteries, originating from the lateral faces of the abdominal aorta, lightly caudal to the origin of the renal arteries; those arteries are straight in their initial path and hightly flexuous when they approach the ovaries; they show, besides, a close relationship with the homonymous vein; $b$ ) each ovarian artery emits a fine tubaric branch; c) lightly caudal to the ovarian arteries, still at the lateral face of the aorta, appear the uterine-tube arteries, right and left, with their straight initial path getting flexuous after. This characteristic is accentuated in the pregnant female, in close relationship with the homonymous vein until reaching the mesometric margin, where it becomes separated in two branches, tubaric and uterine; the uterine branch travels that margin caudally, emitting branches for the uterine wall, until anastomose with the uterine branch of the vaginal artery; d) the vaginal artery, branch of the internal pudendal artery, emits an uterine branch, that follows the mesometric margin, sending branches for the uterine wall, until anastomose with the uterine branch of the uterine-tube artery.

Key Words: anatomy, blood supply, genital organs, coendou. 